Murguia, D., and Urbina, A. (2018). "Complex Production Systems: Non-Linear and Non-Repetitive Projects." In: Proc. $26^{\text {th }}$ Annual Conference of the International. Group for Lean Construction (IGLC), González, V.A. (ed.), Chennai, India, pp. 858-868. DOI: doi.org/10.24928/2018/0222. Available at: www.iglc.net.

\title{
COMPLEX PRODUCTION SYSTEMS: NON-LINEAR AND NON-REPETITIVE PROJECTS
}

\author{
Danny Murguia ${ }^{1}$, Alonso Urbina ${ }^{2}$
}

\begin{abstract}
In most residential building construction, the production system design relies on the assumption of linearity per zone and per story, thus, takt-time schedules and flow lines are produced accordingly. However, in practice, such smoothness is difficult to achieve due to non-linear and non-repetitive projects. This research aims to identify the main challenges of the production system design when a planning team faces such projects. To achieve this objective, lean scheduling methods are analysed by a complex production system framework including: variety of tasks, task interdependence, supply chain interdependence, and work density. Two simulation case studies are presented. First, the finishing phase of a residential building presents the case of a non-linear project. Second, the structural works of an industrial project presents the challenges of a non-repetitive project. The main finding is that non-repetitive projects can be handled as multiple repetitive non-linear stages. However, the main challenges include the reciprocal interdependence between trade contractors, the work density disparity between locations and trades, the capacity buffer design, and production rates predictions for the assembly of one-off products. This research contributes to the understanding of scheduling in projects where the linearity assumption of activities is violated.
\end{abstract}

\section{KEYWORDS}

Complex production system, Flow lines, Non-linear projects, Non-repetitive projects, Production System Design

\section{INTRODUCTION}

Construction projects tend to be categorised as linear, non-linear, repetitive, and nonrepetitive. On the one hand, repetitive linear projects are those in which all the operations and outputs are the same in each location (Mattila \& Park 2003). On the other hand, the

\footnotetext{
1 Assistant Professor, Construction Management \& Technology Research Group (GETEC), Pontifical Catholic University of Peru, dmurguia@pucp.pe

2 Research Assistant, Construction Management \& Technology Research Group (GETEC), Pontifical Catholic University of Peru,aurbina@ pucp.pe
} 
repetitive non-linear projects are characterised by repetitive operations in each location, however, outputs are not uniform in each location. By contrast, a non-repetitive project is characterised by unequal operations and outputs in almost all locations (Arditi et al. 2002). Examples of non-repetitive buildings can be found in hospitals, retail, theatres, museums, and libraries. Housing projects have also non-repetitive parts such as common areas and MEP systems in garages (Valente et al. 2014). Table 1 shows a summary of project's characteristics.

Table 1: Project's characteristics

\begin{tabular}{lccccc}
\hline \multicolumn{1}{c}{ Project } & $\begin{array}{c}\text { Size of } \\
\text { locations }\end{array}$ & $\begin{array}{c}\text { Operations } \\
\text { per location }\end{array}$ & $\begin{array}{c}\text { Resources } \\
\text { per location }\end{array}$ & Flow & $\begin{array}{c}\text { Outputs } \\
\text { per location }\end{array}$ \\
\hline Repetitive Linear & Equal & Equal & Equal & Smooth & Equal \\
Repetitive Non-linear & Not uniform & Equal & Not uniform & Moderate & Not uniform \\
Non-repetitive & Unequal & Unequal & Not uniform & Turbulent & Unequal \\
\hline
\end{tabular}

Contractually, these projects are managed with Critical Path Method (CPM)master schedules with multiple sectional completion dates (Olivieri et al. 2016). Moreover, in some countries, there are standards that recommend its use as good practices in time management. However, the inability of CPM to analyse the flow in the production system at the operational level is well known. The most criticised aspects are (i) not focusing on the workflow, (ii) neglecting production rates, (iii) omitting the work disparity in locations, (iv) demoting resource management, and (v) inefficient on repetitive projects (Arditi et al., 2002; Olivieri et al., 2018). Takt-Time Planning (TTP) and flowlines arose as scheduling methods to overcome some of these aspects. TTP is a method adapted from the lean manufacturing industry where the takt-time is a parameter that represents the unit of time that a product must take to be produced, in order to satisfy the demand rate (Frandson et al, 2013). The activities in the production line are aligned to the production rate of the bottleneck. Hence, a continuous workflow is defined (Seppänen, 2014). On the other hand, flowline scheduling models the project as a series of hierarchicallydistributed locations which are geometrically defined by the Location Breakdown Structure (LBS). Therefore, activities flow through different locations consistently using the same amount of resources (Seppänen, 2014). LBMS integrates flowline scheduling with CPM in order to preserve the workflow on locations by delaying the start date of tasks (Frandson et al., 2015).

Non-linear and non-repetitive projects are a challenge for contractors. Production teams who apply TTP or flowlines in linear and repetitive project face problems in nonlinear projects due to unequal workload between zones and discrete activities. Moreover, problems intensify in non-repetitive projects due to non-evident locations, one-off activities, complex architectural designs, a combination of structural materials, multiple services, and a variety of specialised trade contractors. Thus, the production system becomes unpredictable and the desired pull-system becomes a push-system. 
There are claims of successful applications of TTP and flowline in non-repetitive projects. Linnik et al. (2013) implemented TTP in a hospital project. They found that takt-time planning is feasible and beneficial, however, it lacks the ability to define locations that have identical labour content for the bottleneck task. Valente et al. (2014) developed guidelines to implement flowlines in common areas of a residential building. However, the case study presented did not represent interactions of activities of a nonrepetitive project. Tommelein (2017) implemented TTP for non-repetitive works in a small healthcare project in a collaborative environment and highlighted work density as an indicator that expresses a unit of time per unit of area. Previous studies have not attempted to use virtual models and automated software to improve the application of flowlines in non-linear and non-repetitive projects. Moreover, there are no studies linking production system design with concepts of complex systems. This research intends to advance in this aspect.

\section{RESEARCH METHOD}

The aim of this research is to (1) develop a framework for complex production systems, and (2) identify the main challenges of production system design in non-linear and nonrepetitive projects. To achieve these objectives, first, a framework for complex production systems is drawn from the literature. Second, data was collected from two existing construction projects including drawings, takt-time and CPM schedules, division of locations, and trade contractors' production rates. Additionally, interviews were conducted with site engineers to identify the work sequence and challenges during the construction stage. The first case study is the finishing phase of a community-housing project which depicts a linear and a non-linear project. Meanwhile, the second case study is an industrial project which depicts a non-repetitive project. Third, projects were modelled using Revit and Tekla, and simulated in Vico Office. Fourth, results were contrasted with the complex production system framework. Finally, the findings are discussed, and directions for further empirical validation are presented.

\section{UNDERSTANDING COMPLEX PRODUCTION SYSTEMS}

Schramm et al. (2006) investigated production systems in complex projects and highlighted that a project's size, client requirements, and cost and time constraints are not parameters to define the complexity level of a production system. Gidado (1996) found that the components of complexity in the production processes of construction can be categorised as (a) complexity in components that are inherent in the operation of individual tasks, and (b) complexity when bringing together different parts to form a workflow. A similar view was shared by Williams (1999), who contended that complexity in construction projects can be regarded as (a) variety of tasks, and (b) degree of interdependencies of tasks. Moreover, the research also found that complexity is also created by the instability of assumptions upon which the tasks are based.

Miranda Filho et al. (2016) argued that a complex product is comprised of different elements that can be managed by the assumption that the whole is equal to the sum of the

parts. Therefore, complex production systems are composed of a variety of sub-systems 
where the focus is upon how these sub-systems interrelate. In complex projects, some sub-systems might be one-off products or tasks which require detailed design, tools for visualisation and simulation, profound understanding, detailed collaborative planning, and strict control during the assembly process. This variety of sub-system shave natural processes during installation. As such, there is a task interdependence that cannot be violated. For instance, a mixed structure of concrete and steel often requires the erection of concrete elements first before proceeding with steel components. Thus, the division of such elements in different areas for takt-time scheduling is difficult to achieve.

Thompson (1967)identified three levels of internal interdependency in organisational structure; pooled, sequential and reciprocal. The least degree of interaction is pooled interdependence in which two units are not dependent on each other but share the same pool of resources. For instance, the rebar installation trade contractor requires resources from the bending and cutting rebar station. However, they allocate two independent crews for vertical and horizontal elements who work in different areas. This is an example of pooled tasks. The interdependence may also be serial and the order specified, with the output of one activity becoming the input of the next activity. This interdependence is sequential such as the main tasks in a master takt-time schedule. Finally, the greater degree of interdependence can be reciprocal in which tasks have a high degree of negotiation to address conflicts. The actions of one task modify the results in the other, which in turn, returns an input to the previous task. This is the case of the pull-planning process, in which reciprocal interdependences become evident as the tasks are unveiled at the operational level. For example, in a reinforced concrete structure, the beam formwork crew installs the horizontal forms and vertical shores. Then, the rebar crew installs the beam rebar. Finally, the beam formwork crew returns to install the lateral forms in parallel with the slab formwork. If these interdependencies are not visible in the pull-planning meetings, process clashes occur in the field.

Bertelsen (2003) contended that considering almost all construction projects are divided into parts that are subcontracted and may be executed in any sequence or even simultaneously, supply chain interdependence is a factor when analysing the complexity of a production system. Supply chain interdependence becomes critical when detailed design is to be completed during the construction stage by the trade contractor of fabricator.

A concept that helps to understand a production system design is "work density". It is defined as the amount of work required by one trade to do their work in a particular area based on the (1) scope of work, (2) trade's size and capabilities, and (3) trade's means and method (Frandson et al., 2015; Tommelein, 2017). Thus, keeping constant trade's methods, crew size, and capabilities, the work density in a non-linear project will be different between locations due to the varying scope of work. Moreover, the work density ina given area of a non-repetitive project will vary from trade to trade due to the variety of sub-systems and diverting methods and equipment required. This disparity is a challenge in the production system design. 


\section{SIMULATIONS AND RESULTS}

\section{CASESTUDY 1}

The first case study will simulate the finishing phase of a five-story community-housing project including the following activities: (1) painting, (2) doors, (3) windows, (4) closets, (5) flooring, and (6) baseboards. The typical story consists of eight identical twobedroom flats. For the analysis, the story will be divided as a linear project with four locations and 2 flats per location. It will also be analysed as a non-linear project assuming four locations with different sizes: 2, 3, 2, and 1 flats per location. The rationale behind this division is that most residential projects have combinations of 1-, 2-, 3-bedroom flats per story. Thus, flats have different sizes and the work density disparity and non-linearity becomes evident. Finishing tasks were broken down and sequenced at the operational level. This process should be collaborative and negotiated with trade contractors in the pull planning process. Figure 1 shows the networking of activities based on Murguia et al. (2016).

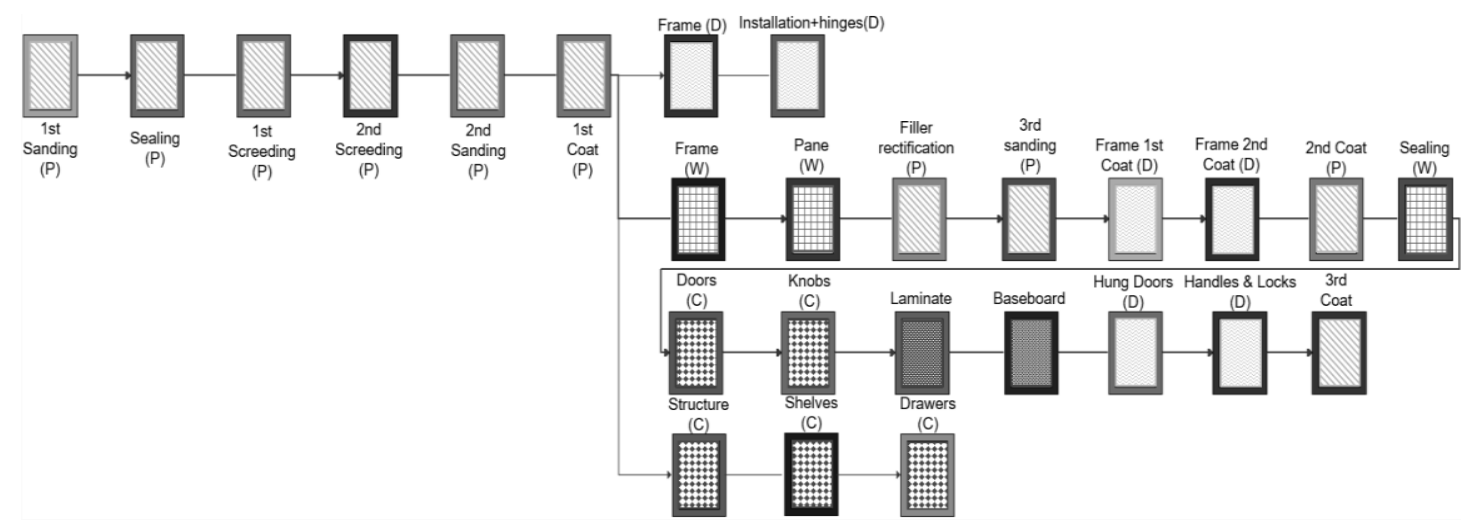

Figure 1: Network of activities (in green painting trade, in yellow doors trade, in blue windows trade, in brown closets trade, and in purple flooring trade)

The next step is to design the number of crews per task and per location in an iterative process. The crew capacity (work density/crew man hours) would help to decide how many crews to allocate in each area. According to Frandson et al. (2015), capacity buffers are preferred in TTP whilst time buffers are preferred in LBMS. To make linear and nonlinear simulations comparable, the number of crews will be defined using a takt-time equal to one day in the linear project with a 10\%capacity buffer. Table 2 shows an example of crew and capacity buffer calculation. None of the iterations exhibit $10 \%$ of a capacity buffer. However, it is decided to use two crews to avoid low productivity. This extra capacity could be further negotiated in practice with trade contractors by means of extra bonuses for on-time completion. 
Table 2: Crew Capacity iterations for First Coat of Painting ( 1 crew=1.5 workers)

\begin{tabular}{ccccccccc}
\hline Item & $\begin{array}{c}\text { Yield } \\
\left(\mathbf{m h} / \mathbf{m}^{2}\right)\end{array}$ & $\begin{array}{c}\text { Take- } \\
\text { off } \\
\left(\mathbf{m}^{2}\right)\end{array}$ & $\begin{array}{c}\text { Work } \\
\text { Density } \\
(\mathbf{m h})\end{array}$ & $\begin{array}{c}\text { Number } \\
\text { Crews }\end{array}$ & $\begin{array}{c}\text { Number } \\
\text { Workers }\end{array}$ & $\begin{array}{c}\text { Planned } \\
(\mathbf{m h})\end{array}$ & $\begin{array}{c}\text { Crew } \\
\text { Capacity } \\
(\%)\end{array}$ & $\begin{array}{c}\text { Capacity } \\
\text { Buffer } \\
(\%)\end{array}$ \\
\hline 1 & 0.07 & 419.87 & 28 & 1 & $1.5(2)$ & 16 & 175 & -75 \\
2 & 0.07 & 419.87 & 28 & 2 & 3 & 24 & 117 & -17 \\
3 & 0.07 & 419.87 & 28 & 3 & $4.5(5)$ & 40 & 70 & 30 \\
\hline
\end{tabular}

Table 3 shows the crew capacity of the painting contractor per location in the linear and non-linear simulation considering a takt equal to one day. The capacity buffer ranges from $-80 \%$ to $58 \%$ with critical crew capacity in location 1 . To deal with this design problem some solutions might be proposed. First, allocating an additional crew only for location 1, however, it is not viable in practice as trade contractors prefer constant labour in the field. Second, changing the boundaries of locations, however, the deliverables in the finishing phase are individual flats. Thus, if we restrict one-day takt in the non-linear project, there will labour instability across locations. The flowline method, which assumes constant resource use, will be used.

Table 3: Crew Capacity in linear and non-linear project for the painting trade contractor

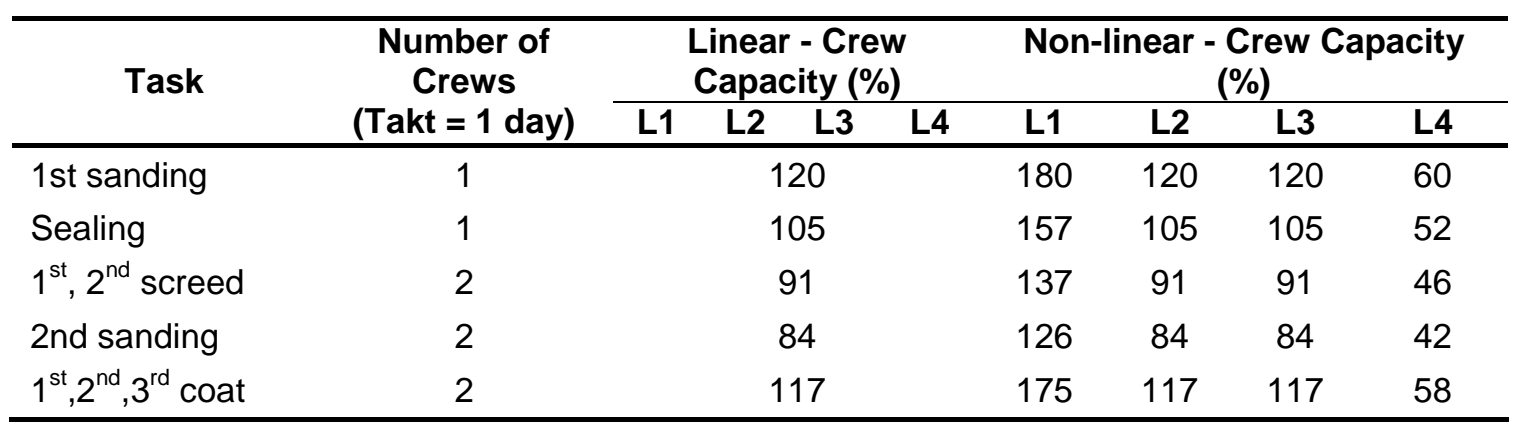

Figure 2 shows the flowlines of the non-linear project. The varying slopes of a single flowline owe to the different time that crews need to complete a task in a location. In this simulation, the flowline schedule (98 days) exceeded in $8 \%$ the takt-time schedule (91 days). Planners can decide between TTP or flowlines by comparing the schedule difference with the problems that arise with the one-day takt restriction. For example, they might choose TTP if there is workable backlog. 


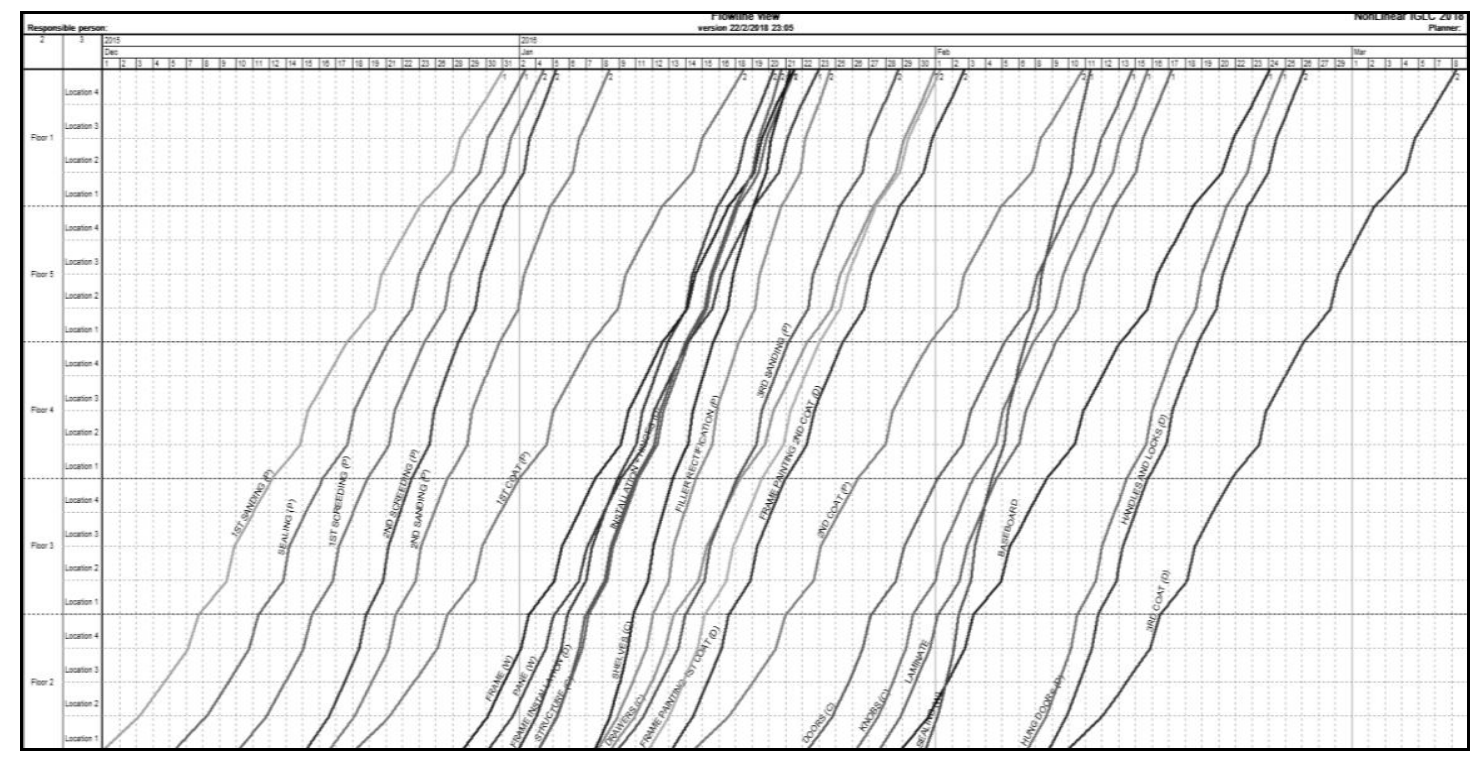

Figure 2: Flowlines of the non-linear project

\section{CASE STUDY 2}

The second case study is a small industrial project with a mixed structure of concrete and steel. The LBS will be defined by (1) foundations, (2) superstructures, and (3) steel roofing as shown in figure 3. The superstructure was divided into (2.1) one-off concrete structures and (2.2) steel structure. A second-level LBS will be established by defining three locations per division. The second case study exhibits the challenges of a nonrepetitive project. This includes one-off products and high levels of supply chain interdependence such as the steel contractor finishing the detailing during construction, a variety of equipment suppliers, and off-site fabrication. The project will be modelled as a non-repetitive project (e.g. superstructure steel contractor does not start activities until all foundations are finalised) and as a repetitive project (activities running smoothly in each second-level division). 


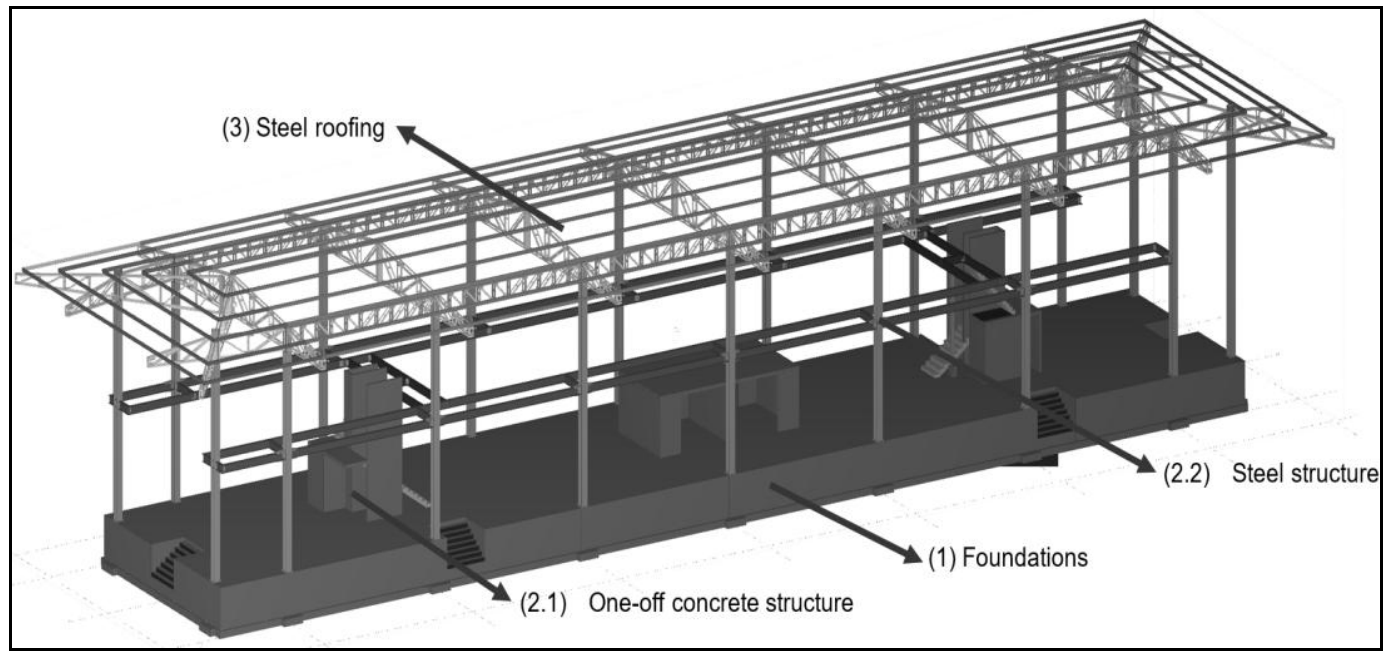

Figure 3: Scope of the non-repetitive project

CPM master schedules for non-repetitive work are produced based on contractual stipulations (e.g. individual work packages contracts) that force trade contractors to start only when their predecessors have fully finished. For example, MEP trade contractor must wait until steel roofing trade contractor concludes. Thus, the project is divided into several independent stages depending on the variety of sub-systems in which each trade contractor works independently from others. This becomes critical when one-off products are to be installed. As a result, the more sub-systems, the more stages in the master schedule and the project duration is extended.

Structural steel assembly could be regarded as a linear process due to the great number of similar components that follow a sequential interdependence. However, activities at the operational level have high levels of uncertainty, negotiation, and supply chain interdependence. For instance, it depends on the resource availability (fabricator), equipment usage (supplier), joints configuration (designers), the relative position of the worker and the component (method and safety), and access (site layout). Thus, productivity rates vary from projections and negatively impact the work density per location and per crew, which in turn leads to significant delays.

Crew design also becomes a challenge as it is not economical nor productive to allocate crews for each component type or unique task. As such, crews can be defined as permanent members and floating members who will assist the permanent members when it is required. Thus, multi-tasking workers could be necessary when planning a nonrepetitive project. Figure 4 shows the flowline schedule with three independent major stages (1) foundations, (2) one-off concrete products, and (3) steel structure assembly, with a total project duration of 60 days. 


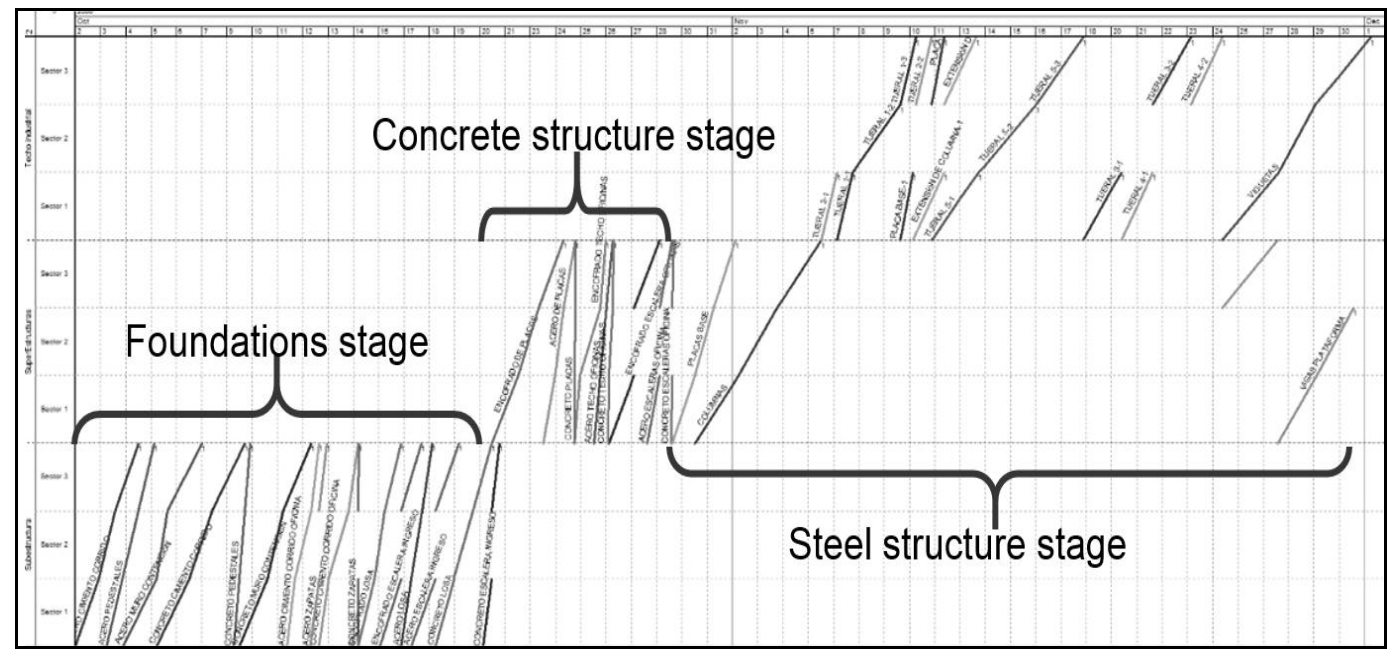

Figure 4: Flowline schedule of the non-repetitive project

A smooth workflow is also simulated by forcing steel trade contractors to start their work as soon as the general contractor finishes the foundations in the first location. As a result, the non-repetitive schedule (60 days) exceeds the repetitive non-linear schedule (50 days) by $20 \%$. Hence, there is an opportunity to treat the non-repetitive project as a repetitive non-linear when the project size justifies the division of products (e.g. foundations) in work chunks. However, a work density disparity is observed between trades in the same location ( $828 \mathrm{mh}$ for foundations, $248 \mathrm{mh}$ for structural columns, and $513 \mathrm{mh}$ for steel roofing).

\section{DISCUSSION}

In the first simulation, a moderate variety of tasks and trade contractors, low levels of pooled interdependence, and high levels of sequential and reciprocal interdependence were observed. Figure 1 shows the sequential way in which different trade contractors perform activities in a single location. Furthermore, it also shows the reciprocal interdependence between painting, closets, windows and door crews. The production system design must also consider some time buffers to address field problems such as crews damaging previous trade contractor's work. One of the main challenges of a nonlinear system is the crew design due to the work density disparity between zones. In practice, it is rare that a trade contractor daily allocates a different number of crews to sustain the flow in non-linear projects. If the number of crews is fixed, there will be high productivity in the bigger locations and low productivity in the smaller locations. Crews might not be able to deal with cycles of random work shifts. Thus, LBMS seems to be a strategy for the production system design as it allows constant resources across locations. However, schedules can be extended. Finally, the supply chain interdependence could be minimised if pre-fabrication of components is allowed in the system. However, this requires standardised design and installation strategies to reduce error and improve quality. 
In the second case study, pooled and sequential interdependences are observed between stages. However, within stages, reciprocal interdependence is low and sequential interdependence is high. As such, 4D modelling is advisable to detect process clashes which can alter the weak workflow. It was also observed that due to the size of the project, the general contractor must finish the foundations before the steel contractor starts the erection of structural columns. However, whenever possible is advisable to split the products into chunks if the project size is large enough to make this possible. One-off products should be collaboratively placed in the schedule as it rarely can be split into chunks. Thus, it is found that a non-repetitive project can be treated as several repetitive non-linear stages. It is also required detailed analysis and iterations to define equal or comparable locations within stages: here, collaborative BIM can be used to good effect. Nonetheless, the challenge is to predict production rates in complex products assembly.

\section{CONCLUSIONS}

This research proposes a framework for production system design for non-linear and nonrepetitive projects using lean scheduling techniques. The focus is on the variety of tasks and their interdependence, the supply chain interdependence, and the work density disparity across areas and between trades. A crucial step is to identify the reciprocal interdependences between trade contractors as this interaction becomes critical in the field. The work density disparity is a key factor in the production system design as it causes high and low productivities in different locations as well as crew's periods of downtime. The simulation suggests that flowlines scheduling method is more suitable when a planning team faces a non-linear project. This is due to the ability of flowlines to deal with constant labour resources and the use of time buffers. However, takt-time planning is advisable when workable backlog is available. A non-repetitive project can be handled as a repetitive non-linear one although quantities and distribution of locations change across stages. However, each location exhibits high levels of variability due to the supply chain interdependence and the difficulty in the prediction of production rates. Therefore, the production system designer lies on how well different concepts from complex systems are put together during the planning stage. Further research would include detailed case studies in non-repetitive and non-linear projects to collect data such as(1) location division in complex architectural designs, (2) reciprocal interdependences, (3) trade contractor labour allocation, (4) crews' flow across locations, and (5) resource variability across locations.

\section{REFERENCES}

Arditi, D., Tokdemir, O.B. \& Suh, K., 2002. Challenges in line-of-balance scheduling. Journal of Construction Engineering and Management, 128(6), pp.545-556.

Bertelsen, S., 2003. Construction as a complex system. In 11th Annual Conference of the International Group for Lean Construction. Virginia, USA.

Frandson, A., Berghede, K. \& Tommelein, I., 2013. Takt time planning for construction of exterior cladding. In P. Formoso, C.T. \& Tzortzopoulos, ed. 21th Annual 
Conference of the International Group for Lean Construction. Fortaleza, Brazil, pp. 527-536.

Frandson, A., Seppänen, O. \& Tommelein, I., 2015. Comparison Between Location Based Management and Takt Time Planning. In O. Seppänen, V. A. González, \& P. Arroyo, eds. 23rd Annual Conference of the International Group for Lean Construction. Perth, Australia, pp. 3-12.

Gidado, K.I., 1996. Project complexity: The focal point of construction production planning. Construction Management and Economics, 14(3), pp.213-225.

Linnik, M., Berghede, K. \& Ballard, G., 2013. An experiment in takt time planning applied to non-repetitive work. In 21st Annual Conference of the International Group for Lean Construction 2013. Fortaleza, Brazil, pp. 609-618.

Mattila, K.G. \& Park, A., 2003. Comparison of Linear Scheduling Model and Repetitive Scheduling Method. Journal of Construction Engineering and Management, 129(1), pp.56-64.

Miranda Filho, A.N., Heineck, L.F.M. \& Costa, J.M., 2016. Lean as a counterbalance to complexity. In 24th Annual Conference of the International Group for Lean Construction. Boston, MA, USA, pp. 133-142.

Murguia, D., Brioso, X. \& Pimentel, A., 2016. Applying lean techniques to improve performance in the finishing phase of a residential building. In 24th Annual Conference of the International Group for Lean Construction. Boston, MA, USA, pp. 43-52.

Olivieri, H., Seppänen, O. \& Granja, A., 2018. Improving workflow and resource usage in construction schedules through location-based management system (LBMS). Construction Management and Economics, pp.1-16.

Olivieri, H., Seppänen, O. \& Granja, A., 2016. Integrating LBMS, LPS and CPM: A Practical Process. In 24th Annual Conference of the International Group for Lean Construction. Boston, MA, USA, pp. 3-12.

Schramm, F.K., Rodrigues, A.A. \& Formoso, C.T., 2006. The role of production system design in the management of complex projects. In 14th Annual Conference of the International Group for Lean Construction. Santiago, Chile, pp. 227-239.

Seppänen, O., 2014. A comparison of takt time and LBMS planning methods. In 2nd Annual Conference of the International Group for Lean Construction. Oslo, Norway, pp. $727-738$.

Thompson, J., 1967. Organizations in action: Social science bases of administration, New York.

Tommelein, I., 2017. Collaborative Takt Time Planning of Non-Repetitive Work. In K. Walsh, R. Sacks, \& I. Brilakis, eds. 25th Annual Conference of the International Group for Lean Construction. Heraklion, Greece, pp. 745-752.

Valente, C.P. et al., 2014. Guidelines for Developing a Line of Balance for NonRepetitive Areas (Common Areas) at a Vertical Residental Building. In B. T. Kalsaas, L. Koskela, \& T. A. Saurin, eds. 22nd Annual Conference of the International Group for Lean Construction. Oslo, Norway, pp. 763-774.

Williams, T.M., 1999. The need for new paradigms for complex projects. International Journal of Project Management, 17(5), pp.269-273. 